\title{
C-TRIZ: The Further Development of TRIZ in China
}

\author{
Tan Runhua* \\ National Engineering Research Center for Technological Innovation Method and Tool, China \\ *Corresponding author: Tan Runhua, National Engineering Research Center for Technological Innovation Method and Tool, China
}

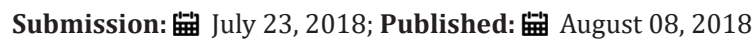

\begin{abstract}
There are two obstacles when the TRIZ is applied by mass-engineers from different companies which are difficult identification of specific problems and transformation of the specific solutions into innovative abilities of the companies. In order to remove the obstacles C-TRIZ, theory of inventive process solving, the new development of TRIZ is being carried out in China. The core concept of C-TRIZ is the inventive process which is seamlessly connected with the main design process for successful application of TRIZ.
\end{abstract}

\section{Introduction}

TRIZ, the theory of inventive problem solving, was formerly developed by Altshulle [1]. The primary purpose of TRIZ was to provide designers with a strategic problem-solving process with a minimum number of trial-and-error iterations [2]. The resolving of inventive problems in TRIZ closely depends on knowledge-based tools such as 40 inventive principles, 76 standard solutions, and eight evolutionary patterns. Figure 1 is a typical TRIZ problem-solving process [3] which involves four steps: determination of the specific or domain problem, abstraction from the specific problem to generic or TRIZ problem, generation of TRIZ solution, generation of specific solution or domain solution. For each step there are methods or tools in TRIZ to support designers or engineers to move ahead.

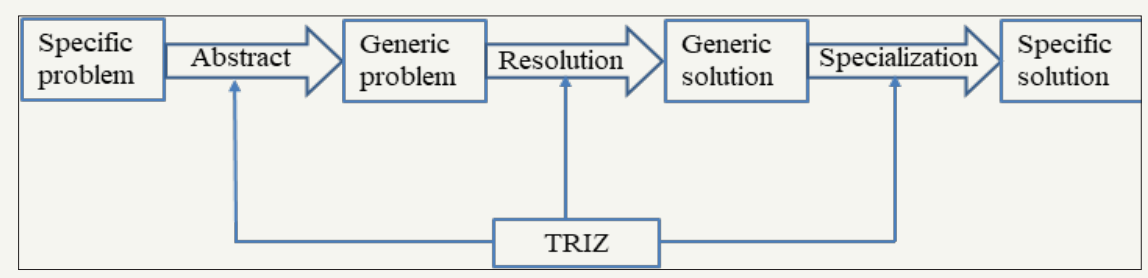

Figure 1: TRIZ process [3].

In the real situation to disseminate TRIZ in industries there are two obstacles to apply TRIZ. The first is that the engineers or designers who use TRIZ at first time find that it is difficult to identify the specific problem which should be similar in meaning to the generic problem. The second is how to apply the specific solutions because they are not the innovations needed by their companies. In order to remove the obstacles we are developing C-TRIZ, the theory of inventive process solving [4].

Figure 2 shows the concept of an inventive process which is core of the C-TRIZ. There are three sub-processes in design process for new product, which are conceptual design, embodiment design and detailed design [5]. RD in the figure is one of the three sub-processes. TA is design task which is the input of the design process. DO is the document which is the design result or output.
The stimulating factors start-up an inventive process, which is one of the unexpected internal or external events, industry or market structure changes, new knowledge or technologies, policy changes and so on. An inventive process is from one stimulating factor that results in the inventive Problem-E. The TRIZ process is used to solve the problem. After the solution is returned to the process RD and the product in being designed is changed. This is the end of the inventive process. The changed design is being processed for the next sub-process. At the last a new product design is formed and stored in DO. It is the advantage that the inventive process is seamlessly connected with the main design process. The massengineers after being trained [6] may apply the process as a kind routine task. As a result they may apply TRIZ successfully in their workplaces. 


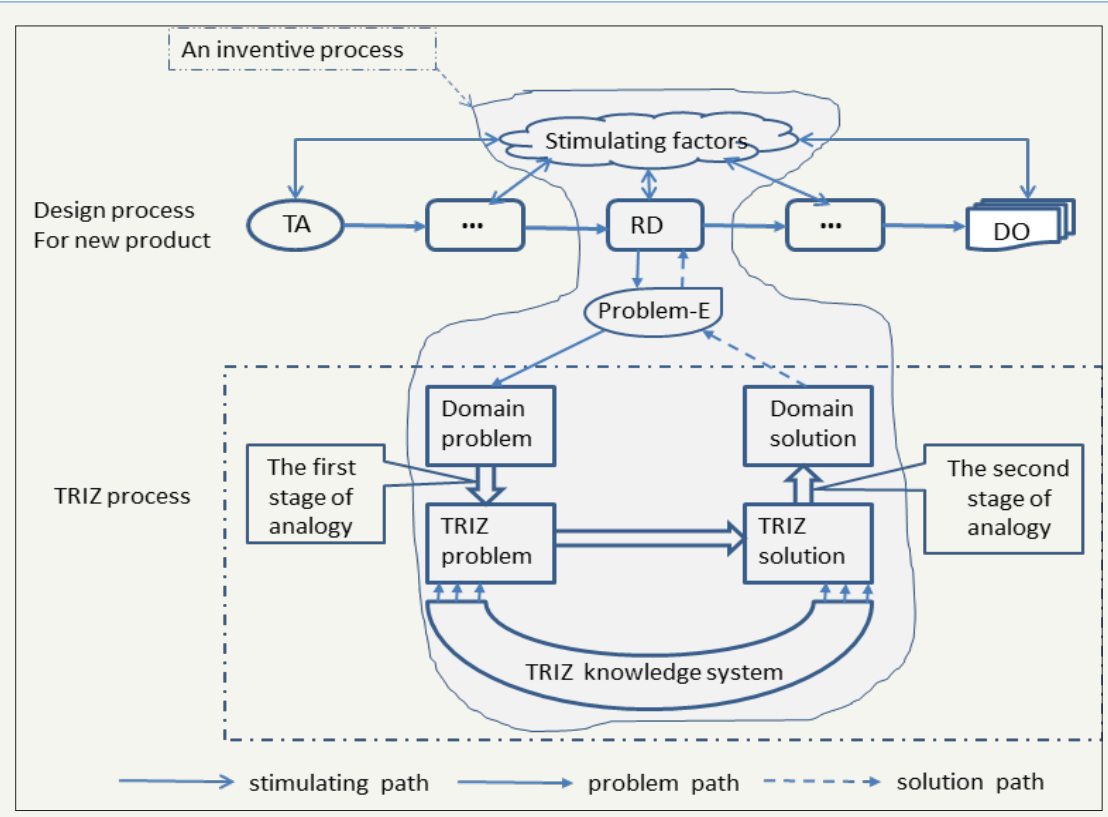

Figure 2: Concept of an inventive process.

\section{References}

1. Altshuller G (1999) The innovation algorithm: TRIZ, systematic innovation and technical creativity. Technical Innovation Center Inc, Worcester, England.

2. Chou JR (2014) An ideation method for generating new product ideas using TRIZ, concept mapping, and fuzzy linguistic evaluation techniques. Advanced Engineering Informatics 28(4): 441-454.

3. Hernandez NV, Schmidt LC, Okudan GE (2013) Systematic ideation effectiveness study of TRIZ. Journal of Mechanical Design 135: 101009 1-101009-10.
4. Tan RH (2017) TRIZ, the development and dissemination in industries in China. TRIZCON 2017, 3-5 October at the Caesars Hotel and Casino in Atlantic City, NJ, USA.

5. Pahl G, Beitz W (1996) Engineering design-a systematic approach. $\left(2^{\text {nd }}\right.$ edn), Springer, London, UK.

6. Tan RH (2014) Interactive training model of TRIZ for mechanical engineers in China. Chinese Journal of mechanical Engineering 27(2): 240248.
Creative Commons Attribution 4.0 International License

For possible submissions Click Here

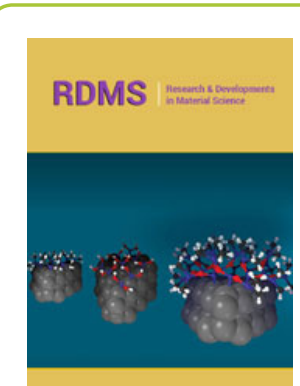

Research \& Development in Material Science

\section{Benefits of Publishing with us}

- High-level peer review and editorial services

- Freely accessible online immediately upon publication

- Authors retain the copyright to their work

- Licensing it under a Creative Commons license

- Visibility through different online platforms 